\title{
Ethical problems experienced by oncology nurses ${ }^{1}$
}

\author{
Kely Regina da Luz ${ }^{2}$ \\ Mara Ambrosina de Oliveira Vargas ${ }^{3}$ \\ Pablo Henrique Schmidtt ${ }^{4}$ \\ Edison Luiz Devos Barlem ${ }^{5}$ \\ Jamila Geri Tomaschewski-Barlem ${ }^{5}$ \\ Luciana Martins da Rosa ${ }^{6}$
}

\begin{abstract}
Objective: to know the ethical problems experienced by oncology nurses. Method: descriptive and exploratory study with a qualitative approach, performed in inpatient units and in chemotherapy out-patients units that provide assistance to oncological patients in two capitals in the South region of Brazil. Eighteen nurses participated in this study, selected by snowball sampling type. For data collection, semi-structured interviews were carried out, which were recorded and transcribed, and then analyzed by thematic analysis. Results: two categories were established: when informing or not becomes a dilemma - showing the main difficulties related to oncological treatment information regarding health staff, health system, and infrastructure; to invest or not dilemmas related to finitude - showing situations of dilemmas related to pain and confrontation with finitude. Conclusion: for the effective confrontation of the ethical problems experienced by oncology nurses to occur, it is important to invest in the training of these professionals, preparing them in an ethical and human way to act as lawyers of the patient with cancer, in a context of dilemmas related mainly to the possibility of finitude.
\end{abstract}

Descriptors: Oncology Nursing; Bioethics; Public Health Policies; Medical Futility; Death; Ethics, Clinical.

\footnotetext{
${ }^{1}$ Paper extracted from master's thesis "Ethical issues experienced by oncology nurses in care in high complexity", presented to Universidade Federal de Santa Catarina, Florianópolis, SC, Brazil.

2 Doctoral student, Universidade Federal de Santa Catarina, Florianópolis, SC, Brazil.

3 PhD, Adjunct Professor, Universidade Federal de Santa Catarina, Florianópolis, SC, Brazil.

4 MSc.

${ }^{5} \mathrm{PhD}$, Adjunct Professor, Universidade Federal do Rio Grande, Rio Grande, RS, Brazil.

6 PhD.
}

Corresponding Author:

Edison Luiz Devos Barlem

Universidade Federal do Rio Grande

Rua Gal. Osório, S/N

Centro

CEP: 96201-040, Rio Grande, RS, Brasil

E-mail: ebarlem@gmail.com
Copyright @ 2015 Revista Latino-Americana de Enfermagem This is an Open Access article distributed under the terms of the Creative Commons Attribution Non-Commercial License (CC BY-NC).

This license lets others distribute, remix, tweak, and build upon your work non-commercially, and although their new works must also acknowledge you and be non-commercial, they don't have to license their derivative works on the same terms. 


\section{Introduction}

Nursing objectives are clearly ethical: to protect patients regarding disrespect to their autonomy, to provide dignified care, and to prevent damage and potential complications by maintaining a healthy environment for patients and their family(1). Similarly, the law on health, an inherent part of nursing goals, has been considered an inseparable element of the nursing professional ethics, including the nurses' efforts to promote the welfare and interests of their patients, aiming to ensure their autonomy in decision-making(2).

In the oncology context, nursing professionals maintain a close contact with situations of pain, finitude and death, physical and emotional side effects, among these hopelessness, anguish, fear and loneliness, intense and denouncing feelings of human fragility, at the same time that an expectation of curing the disease may be present(2).

Oncology is an area of constant ethical problems, experienced from situations already considered part of the professional routine, such as lack of informed consent of patients before diagnostic and therapeutic procedures, the extension of life without concern for its quality, and questionable and heteronomical professional practices ${ }^{(3-4)}$. Regarding the increased use of technologies and medicines for treating oncological patients who no longer respond to available therapies, professionals often experience the life extension of the patient without reacting or positioning ${ }^{(3,5)}$.

All these situations awaken the need of advocacy in health by the nurses, an integral part of the nursing care related to the defense of the rights and interests of patients, avoiding patients and their families to be exposed to a variety of situations that cause suffering. Nevertheless, health advocacy actions, performed by nurses in oncological and palliative care, can be defined as assisting patients and families to overcome the difficulties hindering the path of care, informing and clarifying them as well as defending their choices and acting as a link between them and the health staff(5).

However, many issues experienced by professionals every day are only perceived as organizational problems and conflicts and/or regarding the relationship in nursing and health staff related to directors, managers, patients and their relatives, and not in its ethical dimension. Such conflicts can occur when there are differences in understanding a given situation, which cannot be adequately communicated, understood, and resolved(6).
The ethical problems can be divided didactically into three categories: moral uncertainty, when there is a question on inadequate or incorrect position and a feeling of tension, frustration, and annoyance, but such a situation is not perceived as part of an ethical problem; moral dilemma, which is characterized by two distinct paths to be followed, however, with a single option to be chosen; and moral suffering, situation in which you know what is correct and what should be done, but is prevented from doing so for some reason, either individual, institutional, or social, and you may not follow the path of your conscience ${ }^{(7)}$. More extensive and complex than the division presented, routine plot, present in the oncological context, shows a range of moral issues that cannot always be classified in literature, demonstrating that the ethical dimension remains marked by the need for constant reflections.

Thus, the ethical problems are questions for which the answer is not initially present, and there is no way of knowing whether and how it might be resolved and, therefore, the question is not only about the choice between two or more possible answers, but also about searching a unique and appropriate response to each situation $^{(8-10)}$.

Thus, it is appropriate to recognize the ethical dimension of the problems experienced by Oncology nurses, stimulating them to reflect and question the realities presented, justifying this study. Taking this into consideration, we aimed to know the ethical problems experienced by Oncology nurses.

\section{Method}

Descriptive and exploratory study with a qualitative approach, performed in inpatient units and in chemotherapy out-patients units that provide assistance to oncological patients in two capitals in the South region of Brazil. The criteria for the selection of participants was limited to: be a nurse; develop assisting activity with adult oncological patients; not be on vacation or with a license; and have a year or more of experience in Oncology, considering that a contact less than this period of time may not be enough to experience and identify situations of ethical problems.

Eighteen nurses participated in this study, selected by non-probabilistic sampling, snowball type ${ }^{(11)}$. Thus, the initial participants were chosen in each of the capitals selected for this study, requesting that, at the end of their interviews, they indicated other participants with the characteristics required to the research. The 
number of nurses was not predetermined, in such a way that the number of participants has occurred through repetition of data(11).

Data collection was performed by two interviewers who had the title of nurses, trained for this research, in March, 2013, at different places and times, indicated according to the preference of the participants. Semistructured interviews were carried out, recorded and transcribed, focusing on the possible situations that may cause ethical problems in oncological care.

For data analysis, we used the thematic analysis from the proposed objective. Hence, in the first analysis the full transcript of the interviews and their prior reading occurred, identifying key elements. This was followed by the expanded reading of testimonials, in-depth analysis, and grouping of key elements, defining the categories of analysis by the researchers responsible for the project. Finally, we composed a descriptive structure that formed each of the two categories presented as follows ${ }^{(11)}$. All ethical precepts of Resolution 466/12 were followed. The study obtained approval by the local Research Ethics Committee, with issuance of the Protocol of Approval no 204,293 . Participants were identified by the names of Greek gods and goddesses.

\section{Results}

From the data analysis, we managed to identify two categories regarding the experience of ethical problems in Oncology: when informing or not becomes a dilemma; to invest or not - dilemmas related to finitude.

\section{When informing or not becomes a dilemma}

This category presents situations regarding the transmission of information and guidance in the oncological context, and the dilemmas related to the lack or incompleteness of information. Yet, it presents problems resulting from inadequate infrastructure and the little effective and resolutive health system, creating dilemmas and moral suffering among professionals of different health staffs.

One of the main dilemmas evidenced by nurses refers to the matter of informing or not, as well as guiding the patient and their family members, which may be enhanced by the difficulty of the family in accepting the information.

Most of the time these people are not prepared, they have no knowledge of what they will suffer with the chemo, no matter how you explain that it makes you nauseous, that your hair will fall. One thing is for you to say that when the person still has hair, another is when you have to, someday, go there and have to shave that hair because it is falling (Metis).

Patients will have to be palliative, but do they know what palliative means? Do they know they are going to have palliative care? No! The relative call saying that the father has a fever, pain, almost dying at home. What do they do? Where do they go? And then you say this: ah, but that's right, that's the disease, the best you can do is going to the emergency. You know, like this, but they don't have that preparation for palliative care at home, they were not guided, they were not prepared, they were not given this information (Pandora).

In addition, we can show that the nurses realize that there is a relationship of uncertainty when it comes to the medical cancer-related diagnosis and prognosis, and they need to advocate for patients, acting as a link between them and other health staff members, ensuring they are informed and clarified about their care. However, often, these situations may not be recognized by nurses as ethical problems, which can compromise patient advocacy actions.

The doctor knows the diagnosis, the staff knows the diagnosis, and the patient knows it in a different way, and I, as a nurse, try to clarify something that is in my power, but I can't interfere with a medical diagnosis [...] and the doctor sometimes says: - but I already told him what he's got, he's understanding that the way he wants to. And I say: - but, doctor, he thinks he has something else! - that's his problem, is what he's understanding, I told him what he's got. There are other doctors that we have a giant facility to ask and he goes there, stops everything he's doing and explains to the patient again (Pandora).

The fragile communication and interaction between the different professionals who are part of the health staff show itself as an important source of ethical problems, making many decisions not to be taken as a team, or even based on desires of the patients, which can compromise the quality of the care and the autonomy of the oncological patient.

There are communication problems in the nursing/doctor/ patient relationship, which generates doubt and insecurity, and damages the professional-patient link (Bia).

Nursing disunion is real and important, we take our focus from the patients, I think if the thought was focused on them, many problems would not exist, you know? Rivalry between the staff, the absence of the doctor, the nursing, the technician, the nutrition professional. There is a lack of unity among us (Hestia).

The absence or incompleteness of the records held by the health staff also weaken the care to oncological patients, since it can hinder the continuity and quality of the provided 
care as well as prevent the support regarding situations in which professional practices need to be evaluated.

Sometimes you don't have a good evolution of the medical staff that can be supported. We know that the patient is support, is palliative care, but this isn't evolved and the medical staff didn't talk to the family (Nemesis).

The recognition of inappropriate situations related to professional negligence, unpreparedness, and incompetence can lead nurses to experience moral suffering, confronting their values and beliefs regarding the care they provide to patients, with the difficulties imposed by the staff and the health care system.

What bothers the most is when we see the patient being mistreated, it's not the patient's loss, death, or illness, but the suffering itself. It's knowing that the patient has the right to what should have been done and it hasn't because your colleague was negligent. What bothers me and makes me suffer is the lack of ethics, lack of respect. [...] All situations in which we're powerless cause a discomfort to us, either because we can't provide what the patients need, or because we know they weren't assisted as best as they could have been (Eileithyia).

An older adult patient, unaccompanied, came early with the ambulance, spent all day only with lunch, finished what he came to do at the end of the afternoon, he had not made a snack and was even forgotten by the transportation of his city [...] so it generated a suffering in me by seeing that patient abandonment under those conditions (Diceia).

Another thing that's very conflicting is the difficulty of access to the most modern treatments that SUS patients face. Patients with the same pathology, from a health insurance and from SUS have different treatments. The prognosis of the SUS patients could change a lot if they could have a faster access, if they didn't need to enter in judicial process, wait for all these procedures until they could get the medication (Eros).

Another important source of moral suffering refers to the infrastructure of the institution, since nurses find themselves limited to offer patients the minimum infrastructure that enables quality care. In the same way, several times, the nurses reported that they were not able to perform confrontations, and they even have to improvise conditions in such a way that patients receive the required information and care.

There's not, in an oncological hospital, a room for palliative care. Patients die along with those who arrived to do chemotherapy, we don't have that whole concept of palliative care related to oncology. We take courses and we can't put them in practice by lack of structure (Nemesis).

The physical space is tiny for our service [...] I often can't sit in a room to a medical appointment and we make it an open consultation over there in the chemotherapy room (Pandora).

\section{To invest or not - dilemmas related to finitude}

In this category, dilemmas and moral suffering are confronted by uncertainty and certainty related to pain and non-acceptance of human finitude. To experience the treatment of patients who no longer respond to the available therapies, as well as the ineffective coping of the patient regarding the treatment, with doubt of healing and the possibility of death, are conditions that put nurses in a state of vulnerability and impotence.

It is worth conducting a treatment and telling the patients that they'll have a survival rate? A weak patient, unable to eat, vomiting, complaining of pain in the body, for 4 months? Until the patient's death? [...] I have a huge difficulty in determining what survival is (Eros).

Therapeutic obstinacy and futile treatment, because the investment in a patient who does not bear treatment is common, either because the doctor didn't communicate the real situation to the family, or didn't say that the patient cannot be cured, or because the family does not accept losing the loved one [...] these dilemmas have caused me much suffering, because they often make us hostages of that situation, if the doctor didn't tell the truth to the relatives, how are we supposed to tell them? (Aphrodite).

Yet, when it comes to pain in oncology, nurses reported that sedation is an option to provide a terminal process that is less aggressive and suffered, both for the patients and to their family, and to the staff itself. However, the decision to sedate or not the patient may also generate uncertainties, especially when there is no agreement among the staff about the best conduct for the patient: to comfort and accept the finitude or to invest in uncertainty?

That moment of decision between what to do: to sedate, to invests in the patient, to communicate the family, to not communicate. I think this situation is the most conflicted of all because we're in a crossfire with the doctor, the patient, and the family, and what happens sometimes is that we realize that there are some doctors who have more difficulty to decide this, and sometimes the patient will suffer and the family suffers as well (Iris).

\section{Discussion}

The approach to patients with cancer is a difficult task in clinical practice, involving the need to transfer information about their diagnosis, prognosis, risks and benefits of the treatment, in addition to the possibilities of disease progression; in these circumstances, to communicate the news to the patient is a challenging process $^{(12)}$. 
The act of informing patients about their diagnosis is a legal duty of the doctor, as well as the treatment and its risks, allowing patients to express their consent to the treatment. However, it is the responsibility of the nurse to guide and clarify doubts about the diagnosis and the treatment, in such a way that its educational role is fundamental in the assistance provided, since the clarification on several aspects of the disease contributes to a better experience of the patients, decreasing their anxiety(13).

The dilemmas recognized by the nurses interviewed in this study on the decision of informing or not patients and family members can demonstrate that these professionals deny their status as lawyers of the patient, enhancing the occurrence of ethical problems, as nurses who work in oncology care understand that they are advocating, especially when they teach self-care strategies for patients and their families, providing them with clinical information and assisting them in clarifying their anguishes and goals(14).

Yet, the ethical problems highlighted, arising from the fragile interaction and communication between the different health staff professionals, can compromise the quality of the care provided to the patient, considering that health care, under the interdisciplinary perspective, has as an action proposal with a focus on the life of the human being, through collective effort of multiple knowledge. Thus, it should be noted that the integration of knowledge occurs, above all, through dialogue, communication, exchange, mutual respect, synergy, and convergence of ideas, and not simply by juxtaposition of knowledge $^{(15)}$.

Also, the fragile communication evidenced among the staff could compromise the patient's autonomy in decision making, which is often taken without considering their wishes. In the Brazilian context, recently, the doctor-patient relationship was still under a paternalistic and conservative model, however, the emergence of the patient's rights, especially the right to self-determination, motivated doctors to adopt new behaviors $^{(13,16)}$.

In certain specialties, such as in Oncology, these changes have brought new ethical problems ${ }^{(16)}$. In this sense, it is the responsibility of the nurse, as a lawyer of patients, to ensure their right to self-determination, helping them to clarify their desires and perceive their values in a given situation, in such a way that they make their decisions expressing and reaffirming these values ${ }^{(17)}$.

Another important aspect, recognized as a source of ethical problems by nurses, refers to the absence or weakness of the medical records, which should be reliable regarding the performed procedure. However, a study on Brazilian Intensive Care Units (ICU) showed that intensivist professionals avoid registering some procedures, admitting that they omit information in the medical record, either for considering them unnecessary, or for fearing of punishment by the code of ethics and/or criminal law. In addition to the lack of hospital protocols of procedures regarding a patient without hope of cure, such as limitation of vital support, the absence of a clear legislation on the subject contributes to the insecurity of health professionals to carry out their records(18), enhancing the ethical problems in environments of health care to oncological patients.

The recognition of morally inappropriate situations can lead the nurses to experience moral suffering. Several studies indicate that aggressive treatments to terminal patients, unnecessary tests, and inappropriate treatments constitute situations that commonly generate moral distress in health care environments(1,6,19-21), Therefore, oncology nurses can recognize what is the appropriate ethical behavior to be followed, however, due to external pressures, they become unable to continue with the right action path(7).

In addition, when recognizing the precariousness of the infrastructure that comprises the care in Oncology as a source of ethical problems, nurses confirm that inadequate working conditions, such as lack of material resources and/or humans to perform the work of nursing, may be a source of ethical problems, as identified by a study with nursing professionals working in hospital environments ${ }^{(19)}$.

Health disparities may also generate major ethical problems in care to oncological patients, especially due to the difficulty of access to health services or advanced technology. In this sense, the law on health could prove to be an important element to promote user rights that are not respected, and raise the awareness of authorities to the needs and requirements of the population(6,19-21).

In Brazil, health care comprises a dual system in which, even though there is a system of universal access (SUS - Unified Health System), there is another one, 
of differentiated access and that offers a differentiated assistance: the private system. Considering this system, there may be situations of injustices committed in the hospital scenario, against the patients and their family, as well as against health professionals(22).

These situations are related to various processes, such as, for example, the type of coverage offered by the health insurance, resulting in an unequal and unfair assistance, involving them in discriminatory practices, according to the type of coverage to the treatment offered to the patient by the health insurance. Health care quality seems to be related to the scope of coverage of the health insurance, i.e., the health insurance that patients have is what will determine the quality of the care they will receive(22).

It is worth mentioning that Federal Law no. 12,732, of November 22, 2012, establishes a maximum of 60 days for people with cancer to begin the treatment provided by SUS. This period starts from the confirmation of the diagnosis and the inclusion of this information in the medical record, and establishes that patients should undergo surgery or start chemotherapy or radiation therapy, according to the indication given to each case(23).

However, technological advances in medicine sometimes make inaccurate the limit of therapeutic possibilities. The devices that extend life, the extraordinary means applied to the maintenance of biological functions, the duty to make every effort to prevent death, using all means available, created the theoretical possibility to indefinitely delay the moment in which it is possible to recognize the limits of science and technology in the maintenance of life ${ }^{(18)}$.

However, a new critical view, which gives priority to the quality of life and the comfort of the patient, has been replacing an obstinate vision of keeping the patient alive. These changes enable patients without prognosis to evolve a less painful death, creating an honest relationship with emotional support and communication with the patient and their family(18).

In this context, the autonomy of the patient must be valued, since patients have values that are different from those of professionals, and they must be respected. Thus, it is important to conduct a discussion between different professionals of the health staff, then, with the patient and/or family, always considering the ethical and moral assumptions, without losing sight of the particularity of each situation and the possible vulnerability of the individuals, which can compromise their proper decision-making process ${ }^{(23)}$.

Nurses can perform a fundamental role regarding the promotion and protection of the autonomy of the patient, according to a study with oncological patients which identified that when such patients were confronted with difficult decisions about quality versus quantity of life, the nurses were in an ideal position to provide them with clinical information and assist them in clarifying their goals and values. Therefore, the nurses will be working in health law, assisting them to self-determine, rather than comply with their lack of autonomy ${ }^{(17)}$.

Along with the intention to improve the quality of life of the person with cancer, palliative care is seen as a proposal of therapeutic intervention for people with any chronic disease, regardless of the terminal process. Its purpose is to provide living with the disease in a dignified manner and with quality of life ${ }^{(23-24)}$. However, the resistance of some professionals in joining the paradigm of care, when there is no cure, brings the finding of negligence in care for patients with cancer in advanced stage. Given this, some professionals feel distressed, unmotivated, and impotent as a result of unfair and discriminatory practices ${ }^{(25)}$.

Hence, the moral uncertainty is evidenced by insecurity regarding the morality of the action implemented, considering if it is correct or not. The circumstances of life and death, related to the oncological disease process, often extended by technological advances in these environments, become even more replete with situations of uncertainty, moral dilemmas, and moral suffering, situations that occur repeatedly, requiring adequate attention and future studies(6).

\section{Conclusion}

To explore the ethical problems experienced by oncology nurses is a difficult task, considering that many times these situations are not even reflected or understood as a whole, given the human difficulty in dealing with the issues of finitude, compromising patient care.

Issues that are involved in the approach to the patient with cancer, such as communication and appropriate information, are crucial for the quality of care. Furthermore, regarding the ethical problems of Oncology, the paradigm of palliative care, therapeutic 
obstinacy, and oncological pain comprise thematic and terminologies that exceed the simple academic reduction, requiring constant discussion and questionings about life and death, the autonomy of people, and the artificial extension of human life.

To recognize the dimension of ethical problems involved in the approach to the patient with cancer becomes a determining factor for tracing strategies to cope with these problems. We highlight that the results of this study have brought important data for the field of investigations related to care in Oncology, and also the need to develop further research in this area, leading to a discussion about the ethical problems experienced by nurses in the practice of oncology nursing.

\section{References}

1. Corley MC, Minick P, Elswick RK, Jacobs M. Nurse moral distress and ethical work enviroment. Nurs Ethics. 2005 Jul;12(4):381-90.

2. Vaartio $H$, Leino-Kilpi $H$, Suominen $T$, Puukka P. Nursing Advocacy in Procedural Pain Care. Nurs Ethics. 2009 May; 16(3):340-62.

3. Carvalho KK, Lunardi VL. Therapeutic futility as an ethical issue: intensive care unit nurses. Rev. LatinoAm. Enfermagem. 2009 Jun;17(3):308-13.

4. Dalmolin GL, Lunardi VL, Barlem ELD, Silveira RS. Implications of moral distress on nurses and its similarities with Burnout. Texto Contexto Enferm. 2012 Mar;21(1):200-8.

5. Thacker KS. Nurses' advocacy behaviors in end-of-life nursing care. Nurs Ethics. 2008 Mar;15(2):174-85.

6. Barlem ELD, Lunardi VL, Tomaschewski JG, Lunardi GL, Lunardi Filho WD, Schwonke CRGB. Moral distress: challenges for an autonomous nursing professional practice. Rev Esc Enferm USP. 2013 Apr;47(2):506-10.

7. Jameton $A$. A reflection on moral distress in nursing together with a current application of the concept. J Bioethic Inq. 2013 Oct; 10(3):297-308.

8. Vargas MAO, Ramos FRS, Schneider DG, Schneider N, Santos AC, Leal SMC. Hospitalization by court order: ethical dilemmas experienced by nurses. Rev Gaúcha Enferm. 2013 Mar;34(1):119-25.

9. Sorta-Bilajac I, Bazdaric K, Zagrovic MB, Jancic E, Brozovic B, Cengic $T$, et al. How nurses and physicians face ethical dilemmas-the Croatian experience. Nurs Ethics. 2011 May;18(3):341-55.
10. Cohen JS, Erickson JM. Ethical Dilemmas and Moral Distress in Oncology Nursing Practice. Clin J Oncol Nurs. 2006 Dec;10(6):775-80.

11. Minayo MCS. O desafio do conhecimento: pesquisa qualitativa em saúde. São Paulo: Hucitec; 2012.

12. Primo WQSP, Garrafa V. Análise ética da revelação do diagnóstico e tratamento em pacientes com câncer genital ou mamário. Rev Assoc Med Bras. 2010;56(4):397-402.

13. Silva $\mathrm{CMGCH}$, Rodrigues CHS, Lima JC, Jucá $\mathrm{NBH}$, Augusto $\mathrm{KL}$, Lino $\mathrm{CA}$, et al. Relação médicopaciente em oncologia: medos, angústias e habilidades comunicacionais de médicos na cidade de Fortaleza (CE). Ciênc Saúde Coletiva. 2011;16(1):1457-65.

14. Gosselin-Acomb TK1, Schneider SM, Clough RW, Veenstra BA. Nursing advocacy in North Carolina. Oncol Nurs Forum. 2007 Sep;34(5):1070-4.

15. Silva TP, Leite JL, Teixeira ER, Moreira MC, Alcântara LM, Silva IR. A interdisciplinaridade e suas contribuições para o cuidado de enfermagem: revisão integrativa. Rev Enferm UFPE on line. 2013;7(esp):4823-30.

16. Albuquerque PDSM, Araújo LZS. Informação ao paciente com câncer: o olhar do oncologista. Rev Assoc Med Bras. 2011;57(2):144-52.

17. Gadow S. An ethical case for patient selfdetermination. Semin Oncol Nurs. 1989 May;5(2):99101.

18. Gaudencio D, Messender O. Dilemas sobre o fimda-vida: informações sobre a prática médica nas UTIs. Ciênc Saúde Coletiva. 2011;16(1):813-20.

19. Barlem ELD, Lunardi VL, Lunardi GL, TomaschewskiBarlem JG, Silveira RS. Moral distress in everyday nursing: hidden traces of power and resistance. Rev. Latino-Am. Enfermagem. 2013 Feb;21(1):293-9.

20. Barlem ELD, Ramos FRS. Constructing a theoretical model of moral distress. Nurs Ethics. ahead of print Epub 3 Nov 2014. doi: 10.1177/0969733014551595.

21. Dalmolin GL, Lunardi VL, Lunardi GL, Silveira RS, Barlem ELD. Nurses, nursing technicians and assistants: who experiences more moral distress? Rev Esc Enferm USP. $2014 ; 48(3): 521-9$.

22. Berti HW. Da percepção de impotência à luta por justiça na assistência à saúde. Ciênc Saúde Coletiva. 2011;16(4):2271-8.

23. Luz KR, Schmitt PH, Vargas MAO, Morera JAC, Bitencourt JVOV, Fujii CCD, et al. Cuidados paliativos na 
doença renal crônica: uma revisão integrativa. Enferm Foco. In press 2015.

24. Vargas MAO, Vivan J, Vieira RW, Mancia JR, Ramos FRS, Ferrazzo $S$, et al. Redefining palliative care at a specialized care center: a possible reality? Texto Contexto Enferm. 2013 Jul-Sep;22(3):637-45.

25. Rodrigues IG, Zago MMF. Cuidados paliativos: realidade ou utopia? Ciênc Cuidado Saúde. 2010;8(supl):136-41. 